Research Article

\title{
Comparative Study of Thermal Performance of Different Nanofluids in a Double Backward-Facing Step Channel: A Numerical Approach
}

\author{
Shailendra Rana $\left(\mathbb{D}\right.$, Hari Bahadur Dura $\mathbb{D}^{D}$, Sudip Bhattrai ${ }^{(D)}$, and Rajendra Shrestha \\ Pulchowk Campus, Institute of Engineering, Tribhuvan University, Kathmandu, Nepal \\ Correspondence should be addressed to Shailendra Rana; ranashailendra74@gmail.com
}

Received 14 September 2021; Revised 16 November 2021; Accepted 9 December 2021; Published 27 December 2021

Academic Editor: Maksim Mezhericher

Copyright (C) 2021 Shailendra Rana et al. This is an open access article distributed under the Creative Commons Attribution License, which permits unrestricted use, distribution, and reproduction in any medium, provided the original work is properly cited.

\begin{abstract}
Two-dimensional numerical simulations are conducted to study forced convection flow of different water-based nanofluids ( $\mathrm{ZnO}$, $\mathrm{Al}_{2} \mathrm{O}_{3}$, and $\mathrm{SiO}_{2}$ ) with volume fractions $(\phi)=0-5 \%$ and fixed nanoparticle size $\left(d_{p}\right)=20 \mathrm{~nm}$ for Reynolds numbers $(\mathrm{Re})=50-225$ over a double backward-facing step with an expansion ratio (ER) $=2$ under constant heat flux $\left(q^{\prime \prime}=3000 \mathrm{~W} / \mathrm{m}^{2}\right)$ condition using the finite volume method. Results indicate that the local Nusselt number increases with volume fraction and Reynolds number for all working fluids. In comparison to water, the maximum heat transfer augmentation of about $21.22 \%$ was achieved by using water $-\mathrm{SiO}_{2}$ nanofluid at $\mathrm{Re}=225$ with $\phi=5 \%$ and $d_{p}=20 \mathrm{~nm}$. Under similar conditions, the $\mathrm{Al}_{2} \mathrm{O}_{3}$ and $\mathrm{ZnO}$ nanofluids demonstrated $14.23 \%$ and $11.86 \%$ augmentation in heat transfer in comparison to water. The skin friction coefficient decreases with the increase in Re for all working fluids. No significant differences are observed in the values of skin friction coefficient among all working fluids at a particular Re. These results indicate that the heat transfer enhancement has been achieved with no increased energy requirements. In addition, the velocity increases with the rise in $\mathrm{Re}$, with $\mathrm{SiO}_{2}$ nanofluid exhibiting the highest velocity as compared to other working fluids.
\end{abstract}

\section{Introduction}

Heat transfer enhancement has been the topic of great interest for researchers for the past few decades. Several active and passive techniques such as the use of a magnetic field, geometry modifications, use of ribs and baffles, surface roughness, and use of nanoparticles have been utilized to achieve enhanced heat transfer. Among such techniques, nanofluids have been widely employed and are considered to be a new class of fluids with high thermal performance. For example, some of the nanoparticles are $\mathrm{Cu}, \mathrm{ZnO}, \mathrm{Al}_{2} \mathrm{O}_{3}$, $\mathrm{TiO}_{2}$, etc. [1]. They are prepared by suspending nanoparticles such as oxides and metals in the conventional base fluids such as water and ethylene glycol [2]. These nanofluids have gained popularity over the past several years due to wide range of applications in microelectronics, biomedical engineering, combustors, manufacturing, etc.
Our main concern in this paper is the study of flow and heat transfer using nanofluids over a backward-facing step (BFS) channel, which is one of the fundamental problems in fluid mechanics. The BFS geometry is simple but the associated flow dynamics are complexas evidenced by flow separation caused by sudden expansion, forming a recirculation zone consisting of vortices. While such separated flows can be detrimental and undesirable due to energy losses in engineering systems, they have proved to be beneficial in terms of heat transfer enhancement due to enhanced mixing by turbulence. Such separated flows in the BFS channels are evident in several practical engineering applications such as the cooling of electronic components, building aerodynamics, heat exchanger, and diffusers [3].

Over decades, extensive analytical, numerical, and experimental investigations have been conducted on heat transfer augmentation using nanofluids in backward- and 
forward-facing step channels. Salman et al. [4] provided a comprehensive review on convective heat transfer in backward- and forward-facing step channels. Togun et al. [5] numerically investigated the forced convection heat transfer of $\mathrm{Cu}$ /water nanofluid with volume fractions $(\phi)=0-4 \%$ for Reynolds numbers varying from 50 to 200 for laminar regime and from 5000 to 20000 for turbulent regime in a backward-facing step with an expansion ratio of 2 under a constant heat flux of $4000 \mathrm{~W} / \mathrm{m}^{2}$. They implemented the finite volume method with a FORTRAN code to solve the continuity, momentum, energy, and turbulence equations. They found that a peak value of Nusselt number was observed due to formation of recirculation zone behind the step. Increasing Reynolds number caused increment in Nusselt number, with the highest thermal performance achieved about $26 \%$ and $36 \%$ for the laminar and turbulent regimes, respectively. Safaei et al. [6] numerically studied the turbulent forced convection heat transfer of water/functionalized multiwalled carbon nanotube (FMWCNT) nanofluids with volume fractions $(\phi)=0-0.25 \%$ and $\operatorname{Re}=$ 10000-40000 over a forward-facing step channel under heat fluxes ranging from $1000 \mathrm{~W} / \mathrm{m}^{2}$ to $10000 \mathrm{~W} / \mathrm{m}^{2}$. Their results indicated that the rise in Reynolds number and volume fraction caused increment in local heat transfer coefficient. Togun et al. [7] carried out a numerical study to investigate the thermal performance of water-based $\mathrm{Al}_{2} \mathrm{O}_{3}$ and $\mathrm{CuO}$ nanofluids with volume fractions ranging from $1 \%$ to $4 \%$ in a double forward-facing step channel under turbulent flow regime. They concluded that the rise in volume fraction leads to enhancement of heat transfer, with the maximum thermal improvement attained at $4 \%$ volume fraction with the $\mathrm{Al}_{2} \mathrm{O}_{3}$ /water nanofluid. Kherbeet et al. [8] studied the effects of inclination angle and step height on laminar mixed convection flow of ethylene glycol- $\mathrm{SiO}_{2}$ nanofluid with a $25 \mathrm{~nm}$ particle diameter and $4 \%$ volume fraction over a three-dimensional horizontal microscale forward-facing step channel. Their results revealed that the Nusselt number increases with the increase in step height Also, the effect of inclination angle on heat transfer and fluid flow is negligible. Alrashed et al. [9] numerically studied the heat transfer and fluid flow using water/functional multiwalled carbon nanotube nanofluid with weight percentages ranging from 0 to 0.25 for $\mathrm{Re}=1-150$ in a backward-facing step contracting channel. They found that the surface temperature decreased with the increment of Reynolds number and weight percentages. Referring to the work done by Ekiciler [10], the thermal-hydraulic characteristics were investigated using $\mathrm{Al}_{2} \mathrm{O}_{3}$ /water nanofluid with volume fractions $(\phi)=1-5 \%$ at $\mathrm{Re}=100-500$ in a single backward-facing step with an expansion ratio of 2 . He observed that the local Nusselt number rapidly rises to the maximum at the separation point and gradually decreases along the heated wall and an almost fixed shape is attained. However, a peculiar observation was made regarding the behavior of the local Nusselt number along the heated wall in the study done by Abuldrazzaq et al. [11]. In their work, they analyzed the thermal performance of different conventional fluids (water, ethylene glycol, and ammonia liquid) in a double backward-facing step channel at $\operatorname{Re}=98.5-512$ under constant heat flux $\left(\mathrm{q}^{\prime \prime \prime}=2000 \mathrm{~W} / \mathrm{m}^{2}\right)$ using the finite volume method. It was found that the local Nusselt number rapidly increased to the maximum from the first step and gradually decreased along the heated wall. But the Nusselt number dropped to the minimum at the second step corner due to expansion and then followed a similar trend as in the first step region.

Channel flows exist in many industrial applications such as microchannel heat sinks, heat exchangers, and automotive systems. Whether the BFS channel has a single-step or double-step configuration, the key role is played by the recirculation zone in both cases, which affects the thermalhydraulic characteristics in those engineering systems. The formation of multiple recirculation zones could be one of many possible flow situations in such engineering devices [12]. For instance, Nie et al. [13] examined the effects of a baffle by studying the three-dimensional laminar forced convection flow in a backward-facing step. The presence of baffles caused the formation of secondary recirculation zones affecting the heat transfer and pressure drop characteristics. They found that the baffle significantly enhances the heat transfer. Togun [14] indicated a 22\% improvement in heat transfer with the use of a vertical obstacle in a single backward-facing step channel utilizing $\mathrm{CuO}$ nanofluid. These studies dealt with the effects of contraction due to external obstacles as opposed to the expansion problem addressed by Abuldrazzaq et al. [11]. The study of heat transfer characteristics in such expansion problems cannot be ignored in terms of design and theoretical perspectives. Moreover, the exploration of the thermal performance of nanofluids in such configurations requires further attention.

To the best of the authors' knowledge, no studies are available regarding heat transfer augmentation with the utilization of nanofluids as coolants over a rectangular channel having a double backward-facing step configuration. Hence, the present work aims to make a comparative analysis of the thermal performance of the three different water-based nanofluids, namely, $\mathrm{ZnO}, \mathrm{Al}_{2} \mathrm{O}_{3}$, and $\mathrm{SiO}_{2}$ over a double backward-facing step channel under a constant heat flux condition. This work will provide further insights into the existing research and is useful in the optimization of heat transfer rate in cooling equipment. Lastly, the results are presented in terms of Nusselt number, skin friction coefficient, and velocity distribution for all working fluids.

\section{Problem Description and Mathematical Modelling}

2.1. Geometrical Configuration. The forced convective heat transfer problem under consideration is shown in Figure 1. It represents a double backward-facing step channel with an expansion ratio (ER) of 2 . The inlet height of the channel $(\mathrm{H})$ is $4.8 \mathrm{~mm}$. The upstream length $\left(L_{1}\right)$ is $50 \mathrm{~mm}$, whereas the first $\left(L_{2}\right)$ and second $\left(L_{3}\right)$ downstream wall lengths are both equal to $500 \mathrm{~mm}$. The upstream wall and the first step of the lower section and the upper wall are thermally insulated, whereas downstream walls starting from the corner of the first step are heated with constant heat flux $\left(q_{w}{ }^{\prime \prime}\right)=3000 \mathrm{~W} /$ $\mathrm{m}^{2}$. The Reynolds numbers considered in this study range from 50 to 225 for three different nanofluids consisting of 


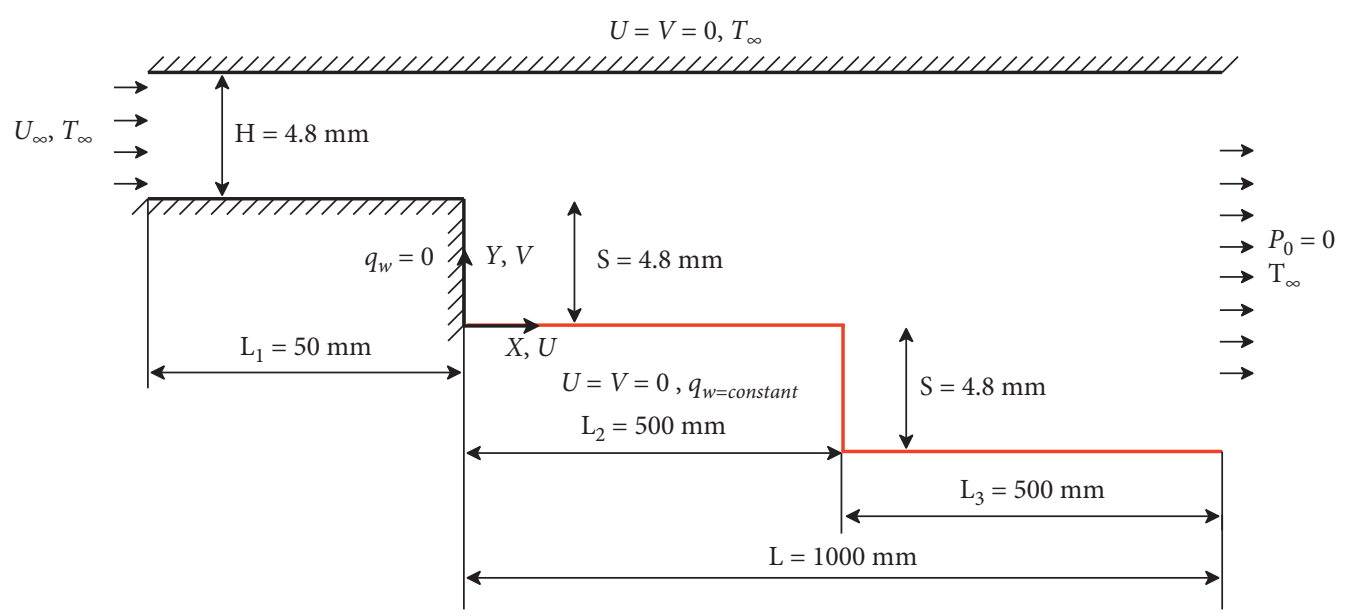

FIgURE 1: Geometrical configuration of double backward-facing step (DBFS) channel.

water as the base fluid and $\mathrm{ZnO}, \mathrm{Al}_{2} \mathrm{O}_{3}$, and $\mathrm{SiO}_{2}$ as nanoparticles each having the size of $20 \mathrm{~nm}$.

No-slip condition occurs between the base fluid and the nanoparticles and they are considered to be in thermal equilibrium with each other. Radiation heat transfer and viscous dissipation are neglected. Also, internal heat generation is not considered in this study.

2.2. Governing Equations. The present study considers the flow to be two-dimensional, steady, laminar, and incompressible. Under such assumptions, the governing equations for continuity, momentum, and energy for a Newtonian fluid can be written as follows [11]:

Continuity equation:

$$
\frac{\partial U}{\partial X}+\frac{\partial V}{\partial Y}=0
$$

Momentum equation:

$$
\begin{gathered}
U \frac{\partial U}{\partial X}+V \frac{\partial U}{\partial Y}=-\frac{1}{\rho} \frac{\partial P}{\partial X}+\nu\left(\frac{\partial^{2} U}{\partial X^{2}}+\frac{\partial^{2} U}{\partial Y^{2}}\right) \\
U \frac{\partial V}{\partial X}+V \frac{\partial V}{\partial Y}=-\frac{1}{\rho} \frac{\partial P}{\partial Y}+\nu\left(\frac{\partial^{2} V}{\partial X^{2}}+\frac{\partial^{2} V}{\partial Y^{2}}\right)
\end{gathered}
$$

Energy equation:

$$
U \frac{\partial T}{\partial X}+V \frac{\partial T}{\partial Y}=-\frac{1}{\rho} \frac{\partial P}{\partial Y}+\alpha\left(\frac{\partial^{2} T}{\partial X^{2}}+\frac{\partial^{2} T}{\partial Y^{2}}\right)
$$

where $v$ is the kinematic viscosity and $\alpha$ is the thermal diffusivity. The Reynolds number has been defined based on hydraulic diameter as follows:

$$
\operatorname{Re}=\frac{\rho U_{\infty} D_{h}}{\mu},
$$

where $D_{h}$ is the hydraulic diameter equal to the channel inlet height and $\mu$ is the fluid viscosity.
Similarly, the Nusselt number $(\mathrm{Nu})$ can be evaluated as

$$
N u=\frac{h D_{h}}{k}
$$

where $h$ is the heat transfer coefficient and $k$ is the thermal conductivity.

The skin friction coefficient $\left(C_{f}\right)$ can be computed as

$$
C_{f}=\frac{2 \tau_{w}}{\rho U_{\infty}^{2}}
$$

where $\tau_{w}$ is the wall shear stress.

2.3. Boundary Conditions. The appropriate boundary conditions in dimensional form associated with above governing equations are presented in the following:

(i) At the Channel Inlet. Velocity inlet condition is applied at the inlet boundary of the channel. The fluid flows with a uniform velocity $U_{\infty}$ and freestream temperature $T_{\infty}$.

(ii) On the Upper Wall. An adiabatic wall with no-slip boundary condition is applied on the upper wall; that is, $U=V=0$ and $T=T_{\infty}$.

(iv) On the Upstream and First Step Walls. An adiabatic wall with a no-slip boundary condition is applied; that is, $U=V=0$ and $T=T_{\infty}$.

(v) On the Downstream Walls. A constant heat flux is applied on the downstream walls with no-slip boundary condition; that is, $U=V=0$.

(vi) At the Channel Outlet. Pressure outlet condition is applied at the outlet boundary.

2.4. Thermophysical Properties of Nanofluids. The nanoparticles used in this study are $\mathrm{ZnO}, \mathrm{Al}_{2} \mathrm{O}_{3}$, and $\mathrm{SiO}_{2}$. Table 1 provides the thermophysical properties of water and the three nanoparticles at $T=300 \mathrm{~K}$. The thermophysical properties under consideration are density, dynamic viscosity, thermal conductivity, and specific heat capacity. The calculation of effective thermophysical properties of the 
TABLE 1: Thermophysical properties of water and nanoparticles at $T=300 \mathrm{~K}$.

\begin{tabular}{lcccc}
\hline Property & Water & $\mathrm{ZnO}$ & $\mathrm{Al}_{2} \mathrm{O}_{3}$ & $\mathrm{SiO}_{2}$ \\
\hline$\rho\left(\mathrm{kg} / \mathrm{m}^{3}\right)$ & 997.1 & 5600 & 3970 & 2200 \\
$k(\mathrm{~W} / \mathrm{mK})$ & 0.613 & 13 & 40 & 1.2 \\
$C_{p}(\mathrm{~J} / \mathrm{kgK})$ & 4179 & 495.2 & 765 & 70 \\
$\mu($ Pa.s $)$ & 0.001 & - & - & - \\
\hline
\end{tabular}

nanofluids has been done using theoretical relations as follows:

(1) Effective thermal conductivity

The effective thermal conductivity can be estimated using the following theoretical model [15]:

$$
k_{e f f}=k_{f}\left(\frac{k_{p}+2 k_{f}-2 \phi\left(k_{f}-k_{p}\right)}{k_{p}+2 k_{f}+\phi\left(k_{f}-k_{p}\right)}\right) .
$$

(2) Effective viscosity

The effective viscosity can be determined from the following empirical correlation [16]:

$$
\mu_{e f f}=\frac{\mu_{f}}{1-34.87\left(d_{p} / d_{f}\right)^{-0.3} \phi^{1.03}},
$$

where $\mu_{e f f}$ and $\mu_{f}$ are the viscosities of the nanofluid and base fluid, respectively. Similarly, $\phi$ is the nanoparticle volume fraction, $d_{p}$ is the nanoparticle diameter, and $d_{f}$ is the diameter of the base fluid molecule.

The equivalent diameter of the base fluid molecule $\left(d_{f}\right)$ can be expressed as follows:

$$
d_{f}=\left[\frac{6 M}{N \pi \rho_{f}}\right]^{1 / 3}
$$

where $M$ is the molecular weight of the base fluid, $N$ is the Avogadro number, and subscripts $f$ and $p$ refer to the base fluid and nanoparticle, respectively. Here, $\rho_{f}$ is the mass density of base fluid taken at $T_{0}=293 \mathrm{~K}$.

(3) Effective density

The effective density of the nanofluid can be approximated by the following correlation [16]:

$$
\rho_{e f f}=(1-\phi) \rho_{f}+\phi \rho_{p},
$$

where $\rho_{f}$ and $\rho_{p}$ are the densities of the base fluid and nanoparticles, respectively.

(4) Effective heat capacity

The effective heat capacity of the nanofluid can be estimated as follows [16]:

$$
\left(\rho C_{p}\right)_{e f f}=(1-\phi)\left(\rho C_{p}\right)_{f}+\phi\left(\rho C_{p}\right)_{p}
$$

where $\left(\rho C_{p}\right)_{f}$ and $\left(\rho C_{p}\right)_{e f f}$ are heat capacities of the base fluid and nanoparticles, respectively.
2.5. Grid Independence Study. Seven progressively refined grids of size ranging from $50 \times 10^{3}$ to $2.4 \times 10^{5}$ elements were generated to carry out the grid independence studies.

Figure 2 shows the grid structure used in this study. All the test simulations have been conducted at $\mathrm{Re}=175$ with water as the working fluid. The variation in the values of average Nusselt number and skin friction coefficient along the heated wall with increasing grid sizes is illustrated in Figures 3(a) and 3(b). It was observed that the changes in the values of the average Nusselt number are less than $0.1 \%$ and those of the average skin friction coefficient are less than 5\% when the grid size is further increased from $1 \times 10^{5}$ to $2.4 \times 10^{5}$. Consequently, the grid consisting of $1 \times 10^{5}$ elements has been selected in terms of computational time and accuracy.

2.6. Model Validation. The computational model has been compared with the results of Al-Aswadi et al. [17] for validation purposes. In their study, they numerically investigated the laminar forced convection of different nanofluids in a backward-facing step. For validation, a comparison of the present results of the velocity profiles for $\mathrm{SiO}_{2}$ nanofluid at $\operatorname{Re}=175$ with $\phi=5 \%$ has been done. Figures 4(a)-4(b) show the comparison between the present results and the published literature of the velocity profiles at different streamwise sections of the channel. The average differences between the present results and the published literature of the profiles of $\mathrm{x}$-velocity at $\mathrm{X} / \mathrm{S}=1.04,1.92,2.6$, and 32.8 are $3.56 \%, 2.23 \%, 3.3 \%$, and $1.56 \%$, respectively. Hence, a good agreement has been obtained with the published literature.

2.7. Numerical Procedures. Computational simulations were carried out to solve the governing conservation equations, that is, equations (1)-(4) with associated boundary conditions using the finite volume method implemented in commercial ANSYS FLUENT 18 software. Structured nonuniform grids have been generated using ICEM CFD for simulation purposes. To account for steep velocity gradients in the recirculation zone near the step, a fine grid has been created in the $x$-direction at both step regions of the channel. But a coarser grid outside and away from the reattachment point has been generated throughout the channel. Similarly, a fine grid is also created in the $y$-direction near the bottom and top walls and the steps. The second-order upwind scheme was employed to discretize all the terms in equations. The coupling of pressure and velocity fields was done by Semi-Implicit Method for Pressure-Linked Equations (SIMPLE) algorithm [18]. More details on SIMPLE algorithm can be found in the works of Patankar [19] and Versteeg and Malalasekera [20]. In this algorithm, the solution process is iterative such that numerical computation is started by initially guessing the pressure field. Then the momentum equation is solved to obtain solution of velocity components. The pressure is then updated using the continuity equation. The solution is said to have converged when the residuals for continuity, momentum, and energy equations reach $10^{-8}$. 


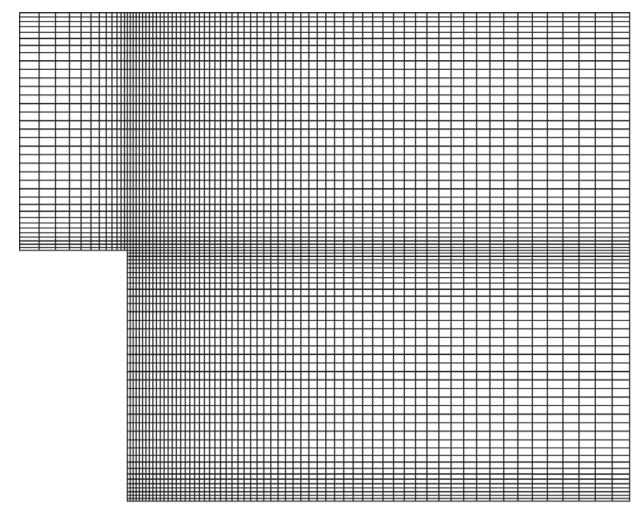

First step region $(\mathrm{A})$

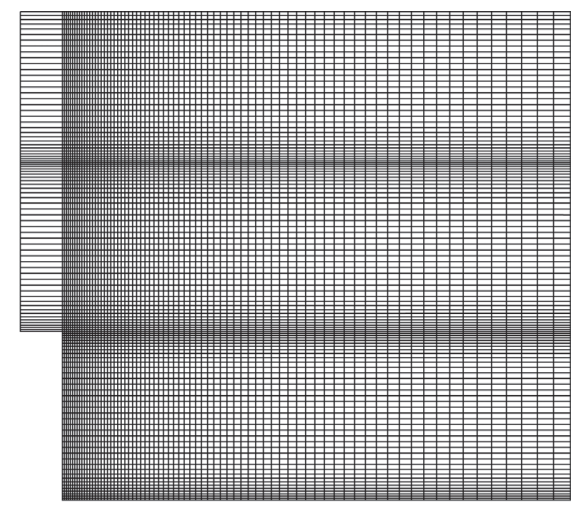

Second step region (B)

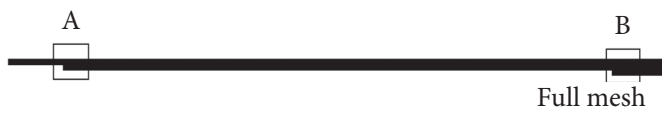

FIgURE 2: Grid structure. (a) First step region. (b) Second step region.

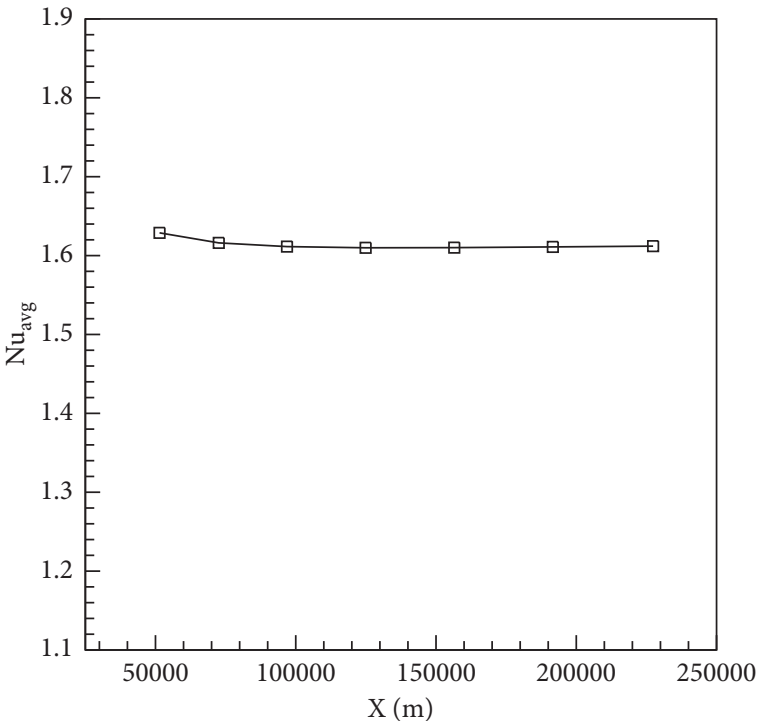

(a)

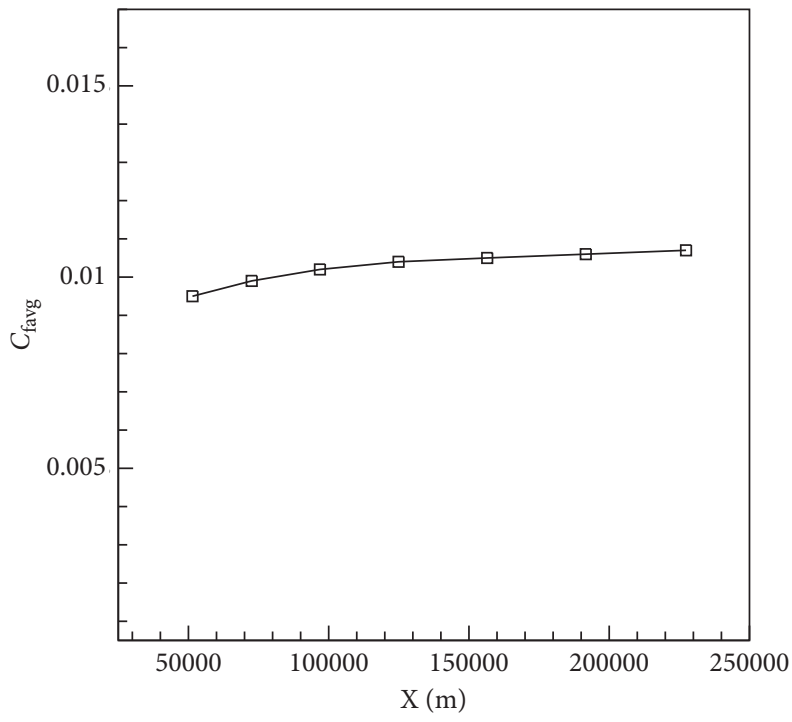

(b)

Figure 3: Variation of Nusselt number and skin friction coefficient with increasing grid size. (a) Average Nusselt number. (b) Average skin friction coefficient.

\section{Results and Discussion}

In this section, the effects of types of nanofluids, volume concentration, and Reynolds number on fluid flow and heat transfer have been investigated in terms of Nusselt number, skin friction coefficient, and velocity distribution.

\subsection{Effects of Different Types of Nanoparticles}

3.1.1. Nusselt Number. A comparative analysis of the influence of three different types of nanoparticles, namely, $\mathrm{ZnO}, \mathrm{Al}_{2} \mathrm{O}_{3}$, and $\mathrm{SiO}_{2}$, with water as base fluid on the Nusselt number is performed at $\operatorname{Re}=225$ with $\phi=5 \%$ and $d_{p}=20 \mathrm{~nm}$ as shown in Figure 5. Starting from the corner between the first step and the heated wall, the Nusselt number steeply rises to reach a peak near the reattachment point and slowly declines along the heated wall, dropping to the minimum near the second step corner.

On the second step, the Nusselt number follows a trend similar to that in the first step region. Such distribution of the Nusselt number is similar for all working fluids as shown in Figure 5(a). Also, our observations regarding the behavior of Nusselt number are consistent with the results of Abuldrazzaq et al. [11]. In comparison to water, the three nanofluids show higher Nusselt numbers among which the $\mathrm{SiO}_{2}$ nanofluid has the highest one due to the highest Prandtl number, followed by $\mathrm{Al}_{2} \mathrm{O}_{3}$ and $\mathrm{ZnO}$. Figure 5(b) demonstrates the average Nusselt number obtained at $\mathrm{Re}=50-225$ for water $(\phi=0 \%)$ and the three nanofluids $(\phi=5 \%)$. It can 


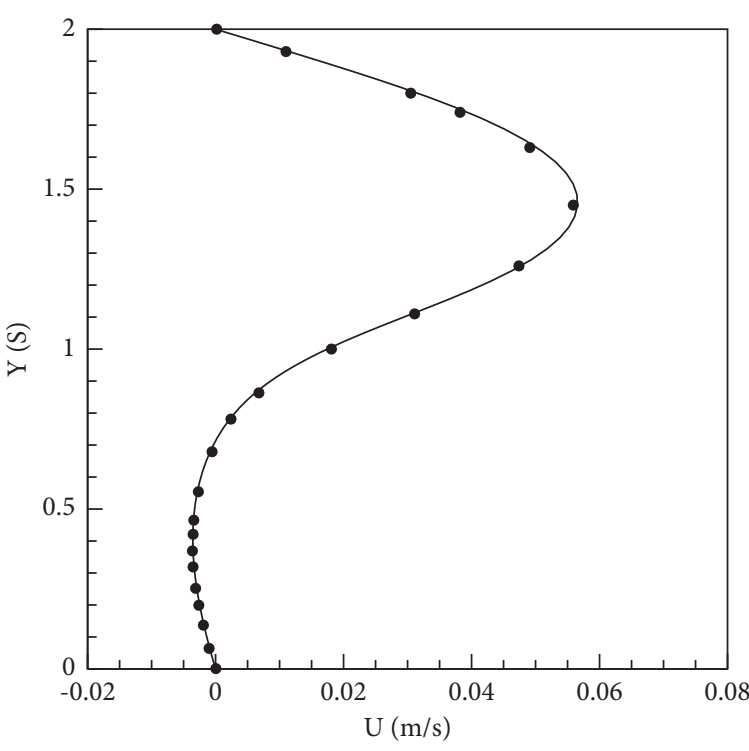

- Al-Aswadi et al. [17]

— Present Results

(a)

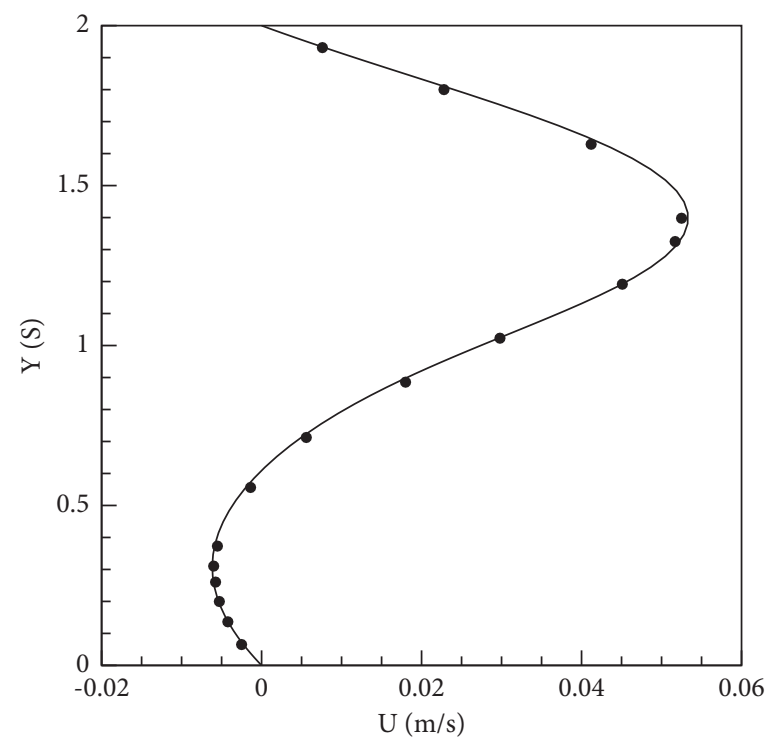

- Al-Aswadi et al. [17]

— Present Results

(c)

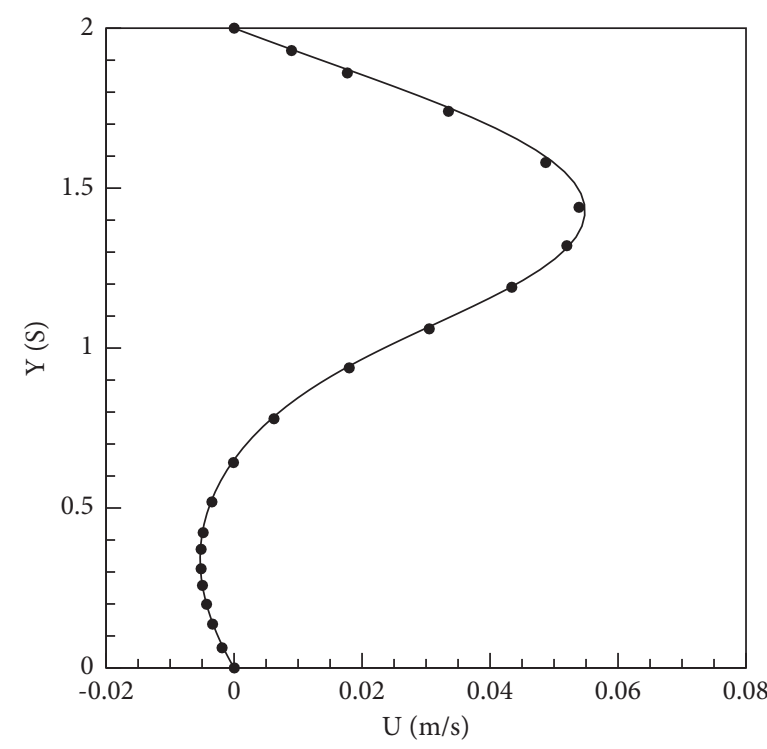

- Al-Aswadi et al. [17]

— Present Results

(b)

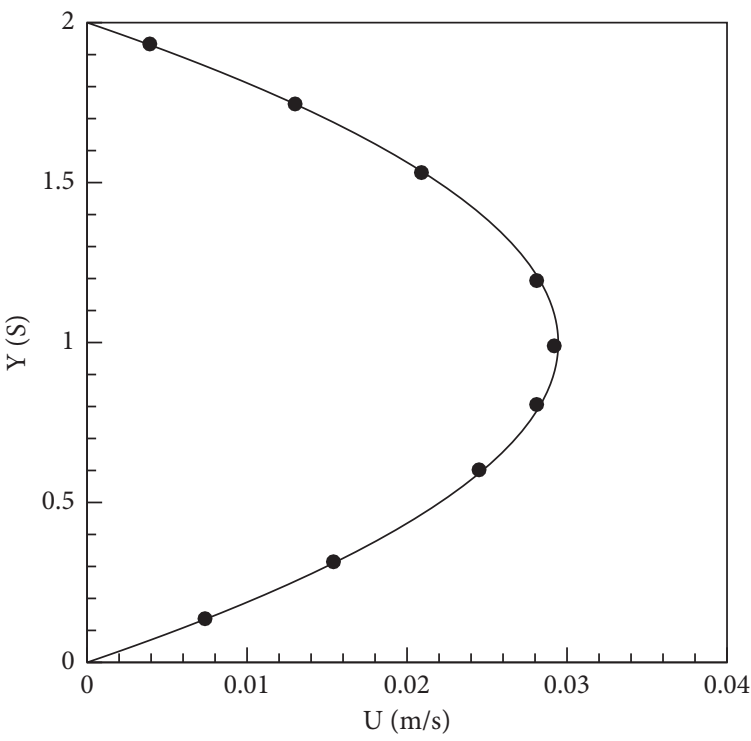

- Al-Aswadi et al. [17] Present Results

(d)

FIgure 4: Comparison of the velocity profiles at different channel sections with the published literature. (a) X/S =1.04. (b) X/S =1.92. (c) $\mathrm{X} / \mathrm{S}=2.6$. (d) $\mathrm{X} / \mathrm{S}=32.8$.

be observed that $\mathrm{SiO}_{2}$ outperforms all other working fluids in terms of heat transfer augmentation at all Reynolds numbers. Also, the contours of velocity for water at $\mathrm{Re}=175$ are depicted in Figures 6(a) and 6(b). To validate these results, the dimensional velocity profiles obtained at different channel sections, that is, $\mathrm{X} / \mathrm{S}=1.04,1.92,2.6$, and 32.8, have been compared with the results presented by $\mathrm{Al}-$ Aswadi et al. [17]. It is observed that our results show a good agreement with the published literature as shown in Figure 7. Major observations are seen at the first and second steps, where recirculation zones are formed due to adverse pressure gradient arising due to sudden expansion. The presence of these recirculation zones at both steps allows proper mixing of the hot and cold fluids, thereby promoting the heat transfer.

3.1.2. Skin Friction Coefficient. Figure 8 depicts the distribution of skin friction coefficient along the heated wall for different nanofluids at $\operatorname{Re}=225$ with $\phi=5 \%$ and $d_{p}=20 \mathrm{~nm}$. 


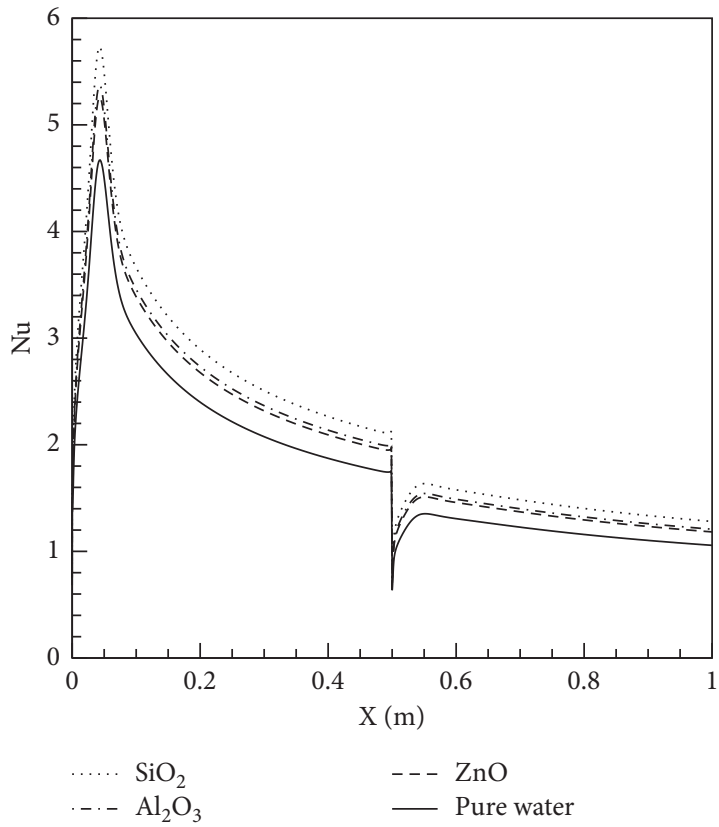

(a)

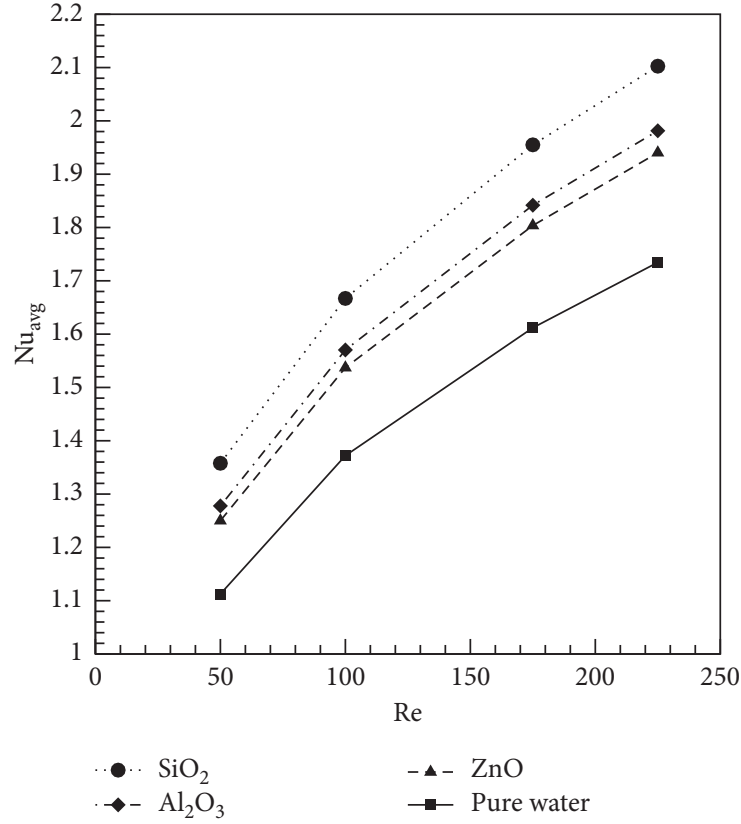

(b)

FIgURE 5: Comparison of Nusselt number between different nanofluids. (a) Local Nusselt number. (b) Average Nusselt number.

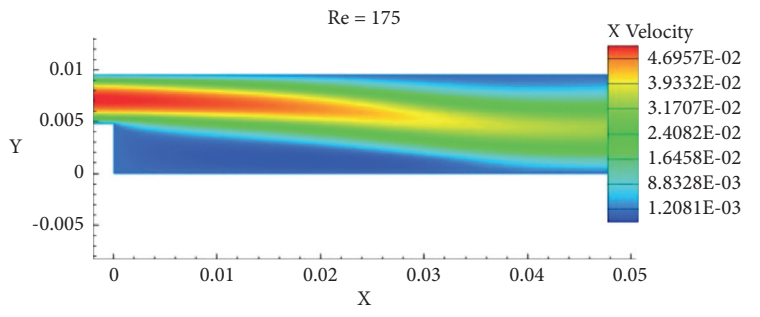

(a)

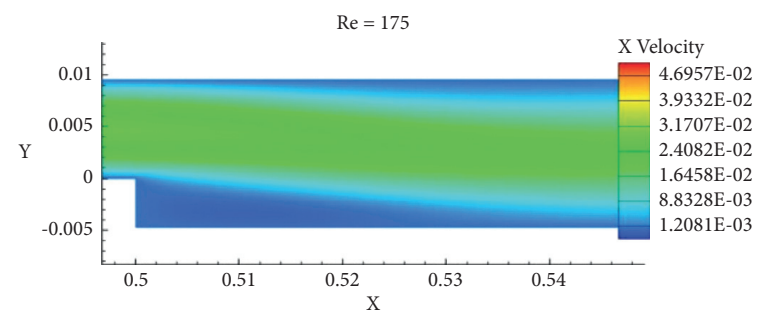

(b)

Figure 6: Velocity contours for water at $\mathrm{Re}=175$. (a) First step region. (b) Second step region.

The results indicate that the distributions of skin friction coefficient along the heated wall are similar for all working fluids. Another important observation is that no significant differences are observed in the values of the skin friction coefficient among all working fluids. This means that these nanoparticles, when dispersed in water, offer almost same contribution to frictional losses, implying similar pumping power requirements.

3.1.3. Velocity Profile. Figures 9(a)-9(d) depict the profiles of velocity for different nanofluids at $\operatorname{Re}=225$ with $\phi=5 \%$ and $d_{p}=20 \mathrm{~nm}$ at different streamwise sections (inlet, $X=0.012 \mathrm{~m}, X=0.505 \mathrm{~m}$, outlet) of the channel. In all sections, it is seen that the $\mathrm{SiO}_{2}$ nanofluid has the highest absolute velocity in comparison to the rest of the nanofluids. This can be attributed to the fact that it has the lowest density among other nanofluids. The flow attains a fully developed condition up to the first step and then separates due to adverse pressure gradient caused by sudden expansion, forming a recirculation zone consisting of vortices as depicted by Figure 9(b).

The flow then redevelops to achieve a fully developed state as it makes way toward the second step. Downstream the second step, the second recirculation zone is formed as evidenced by the profiles of negative velocity depicted in Figure 9(c). While the flow moves toward the channel exit, it reaches a fully developed state shown by the parabolic velocity profile depicted in Figure 9(d).

3.2. Effect of Volume Fraction. The effect of volume fraction on Nusselt number for the three different nanofluids, namely, $\mathrm{ZnO}, \mathrm{Al}_{2} \mathrm{O}_{3}$, and $\mathrm{SiO}_{2}$, at $\mathrm{Re}=225$ with $\phi=1-5 \%$ and $d_{p}=20 \mathrm{~nm}$ is shown in Figure 10. For all nanofluids, it is seen that the increment in the volume fraction of the nanoparticles increases the average Nusselt number, indicating enhanced thermal performance. This can be explained by the fact that the thermal conductivity of the nanofluids increases with the rise in volume fraction. At $\phi=5 \%$, the 


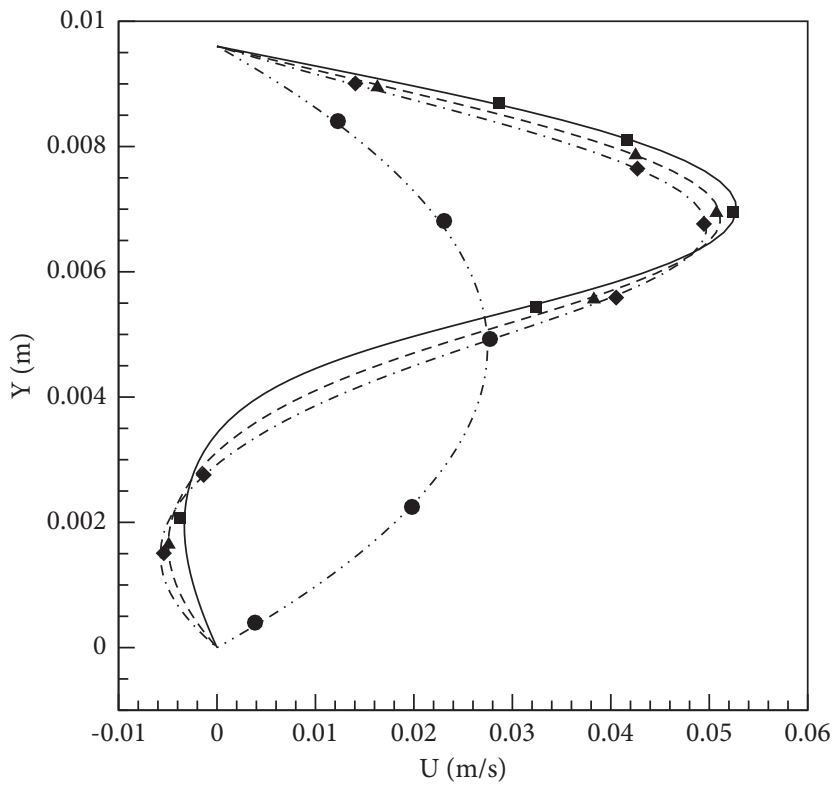

$\operatorname{Re}=175$

- Present Results, $\mathrm{X} / \mathrm{S}=1.04$

- Al-Aswadi et al. [17], X/S = 1.04

- - - Present Results, $\mathrm{X} / \mathrm{S}=1.92$

- Al-Aswadi et al. [17], $\mathrm{X} / \mathrm{S}=1.92$

- . - Present Results, $\mathrm{X} / \mathrm{S}=2.6$

Al-Aswadi et al. [17], X/S = 2.6

... Present Results, $\mathrm{X} / \mathrm{S}=32.8$

- Al-Aswadi et al. [17], $\mathrm{X} / \mathrm{S}=32.8$

FIGURE 7: Comparison of distribution of dimensional velocity profiles for $\operatorname{Re}=175$ at different channel sections with water as working fluid.

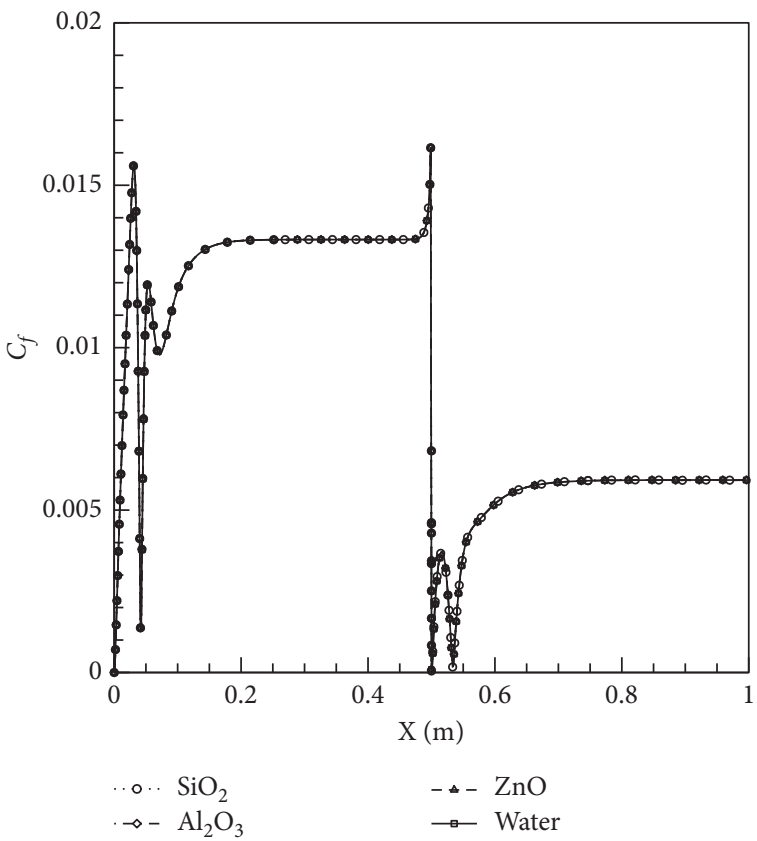

FIGURE 8: Distribution of skin friction coefficient along the heated wall for different nanofluids. 


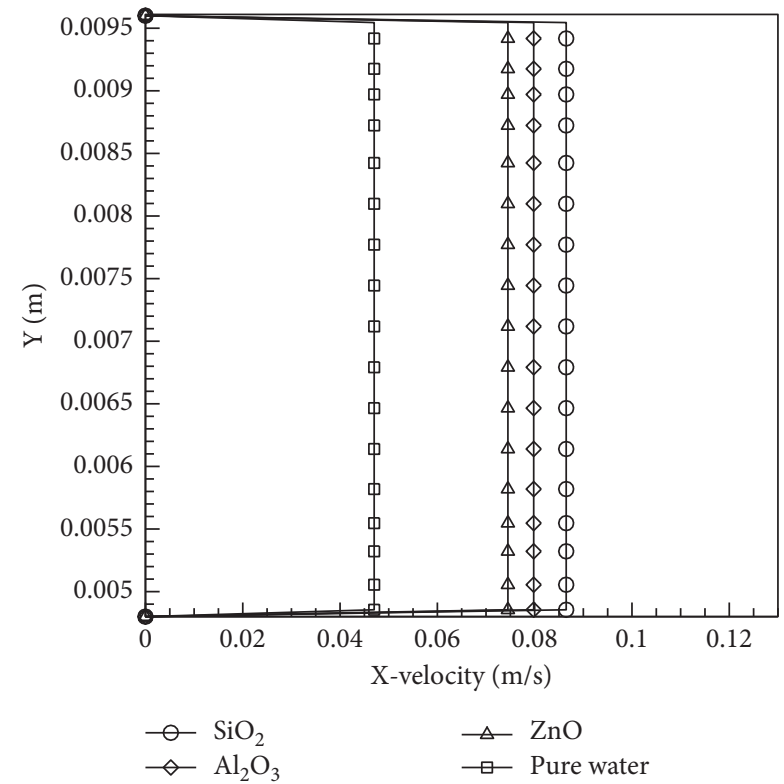

(a)

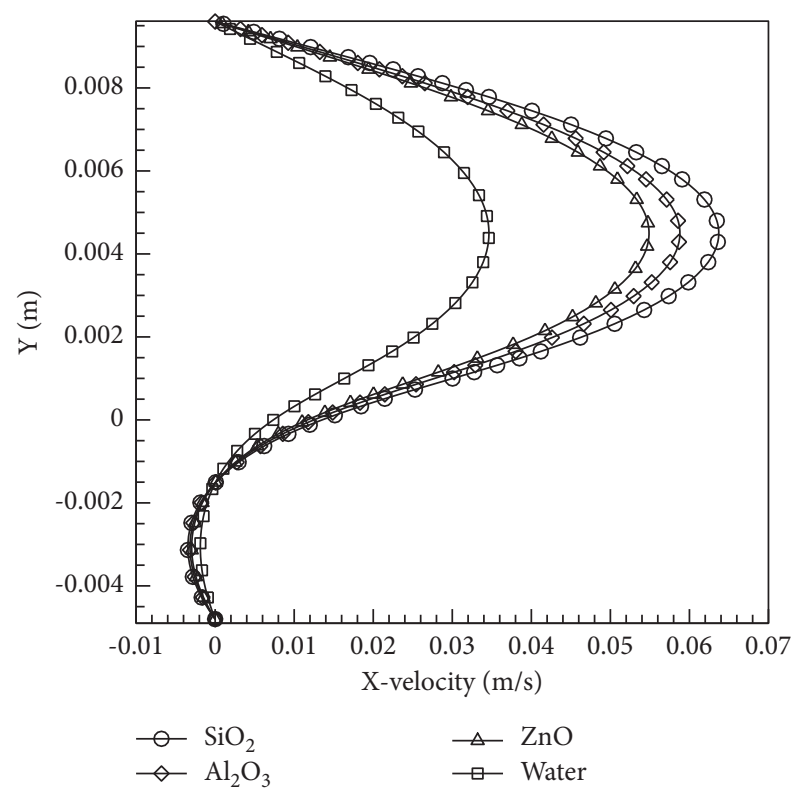

(c)

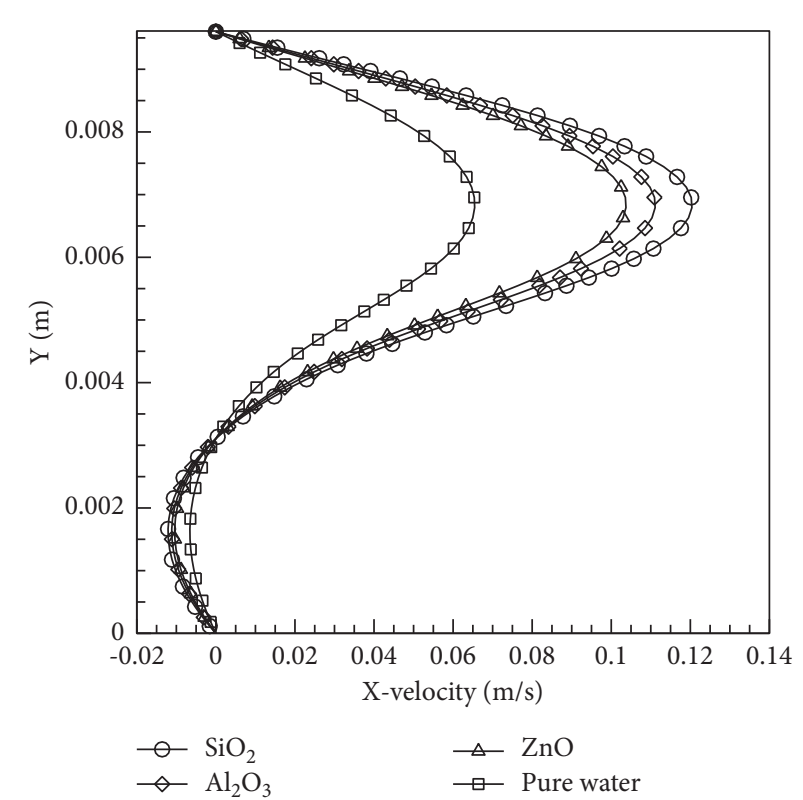

(b)

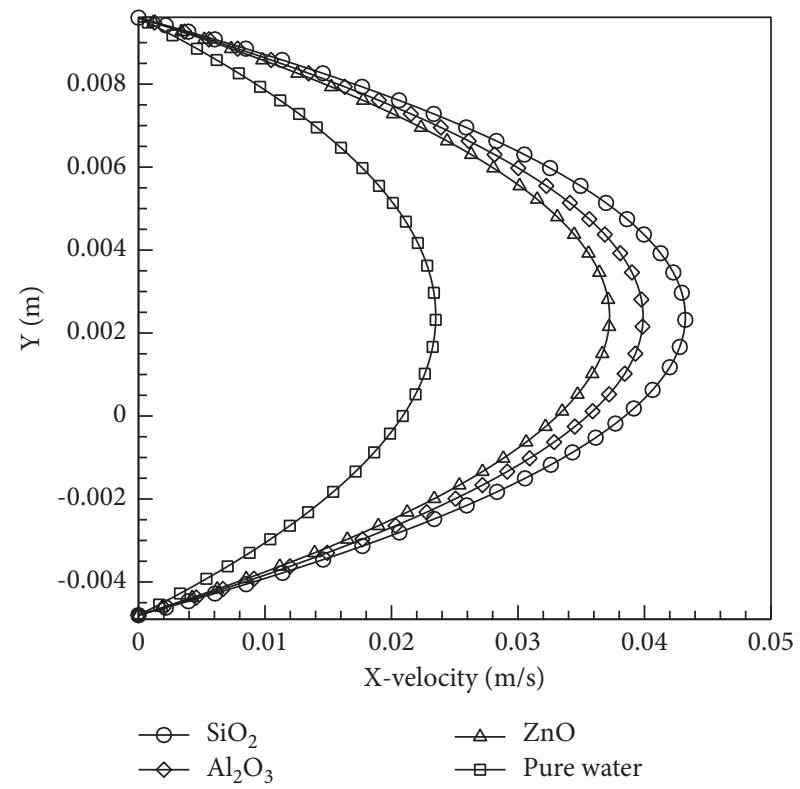

(d)

FiguRE 9: Distribution of velocity profile for different nanofluids at different channel sections. (a) Inlet; (b) $X=0.012 \mathrm{~m}$; (c) $X=0.505 \mathrm{~m}$; (d) outlet.

$\mathrm{SiO}_{2}$ nanofluid demonstrates the highest Nusselt number, followed by $\mathrm{Al}_{2} \mathrm{O}_{3}$ and $\mathrm{ZnO}$.

\subsection{Effect of Reynolds Number}

3.3.1. Nusselt Number. The effect of Reynolds number on Nusselt number for the three nanofluids is studied. Figure 11 shows the variation of average Nusselt number for the three nanofluids at $\operatorname{Re}=50-225$ with $\phi=5 \%$ and $d_{p}=20 \mathrm{~nm}$. For all nanofluids, it can be observed that the average Nusselt number increases with the increment of Re.
3.3.2. Skin Friction Coefficient. The effect of the Reynolds number on the values of average skin friction coefficient for different working fluids is studied. Figure 12 shows the variation of average skin friction coefficient for $\mathrm{Re}=50-225$ with $\phi=5 \%$ and $d_{p}=20 \mathrm{~nm}$. It can be observed that the average skin friction coefficient decreases with the rise in Reynolds number for all working fluids. This is because the velocity of these fluids increases with the increase in Re but the skin friction coefficient is inversely proportional to the velocity.

In addition, at a particular Re, there is no substantial difference in the value of average skin friction coefficient among all nanofluids. For instance, at $\operatorname{Re}=50$, the three 


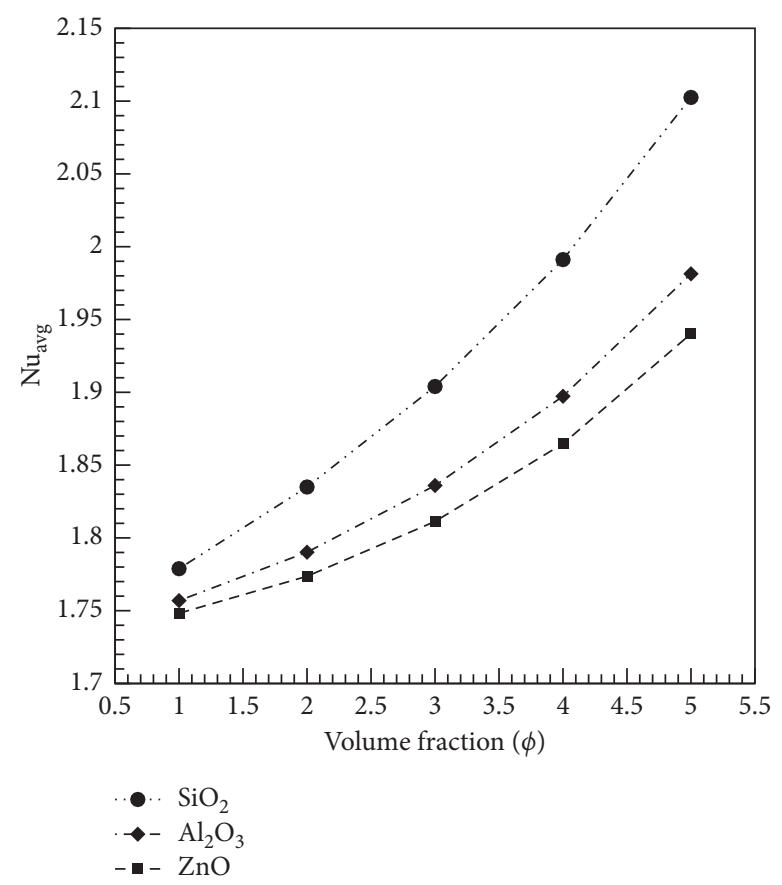

FIGURE 10: Effect of volume fraction on average Nusselt number for different nanofluids.

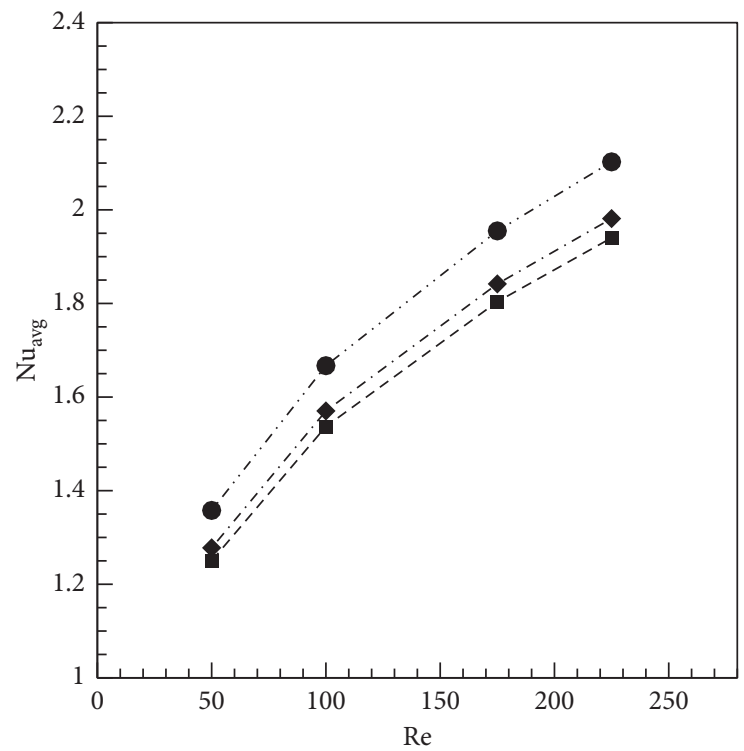

-. $\mathrm{SiO}_{2}$

$\rightarrow-\mathrm{Al}_{2} \mathrm{O}_{3}$

$-\mathrm{ZnO}$

FIGURE 11: Effect of Reynolds number on the average Nusselt number for different nanofluids.

nanofluids showed less than $0.03 \%$ deviation in the value of average skin friction coefficient in comparison to water. Such observations are consistent with the results shown earlier in Figure 8.

3.3.3. Velocity Profile. Figures 13(a) and 13(b) illustrate the velocity contours for $\mathrm{SiO}_{2}$ nanofluid with $\phi=5 \%$ and $d_{p}=20 \mathrm{~nm}$ at the first and second step regions for $\mathrm{Re}=50-225$. It can be observed that the size of the recirculation zones at both steps increases with the rise in Re.

To validate the contours of velocity for the $\mathrm{SiO}_{2}$ nanofluid with $5 \%$ volume fraction, the present results of nondimensionalized velocity distributions for $\mathrm{Re}=50-175$ at different streamwise channel sections, that is, $\mathrm{X} / \mathrm{S}=1.04$, $1.92,2.6$, and 32.8 , have been compared with the results of 


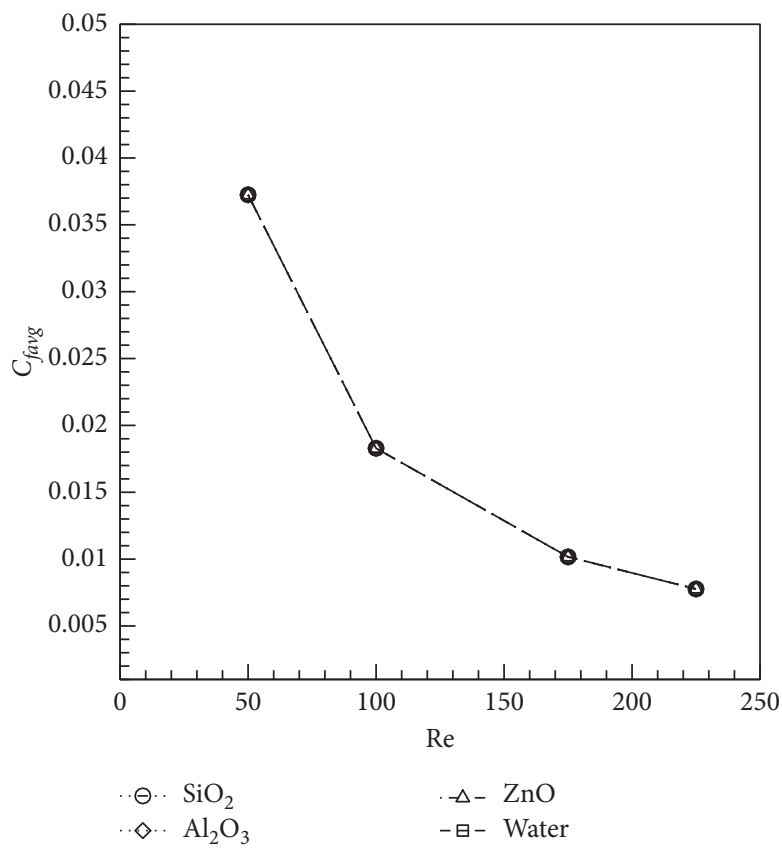

FIgURe 12: Effect of Reynolds number on the average skin friction coefficient for different working fluids.
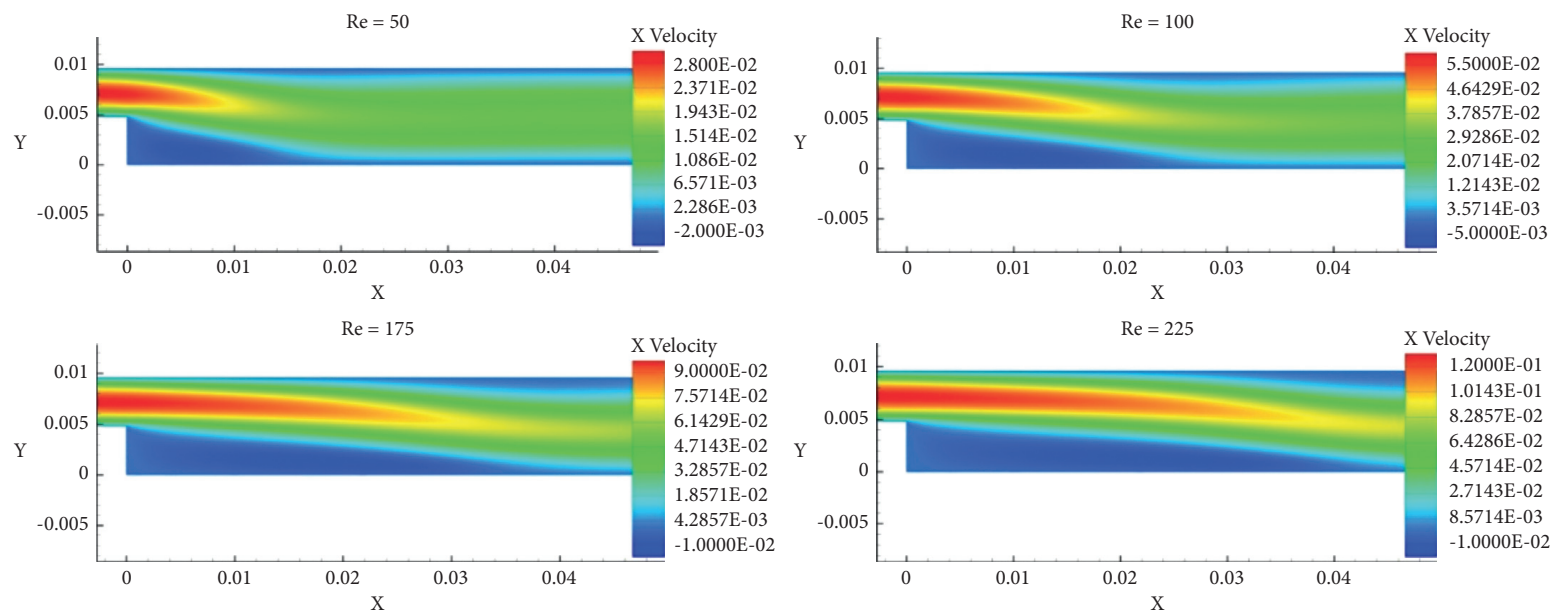

(a)
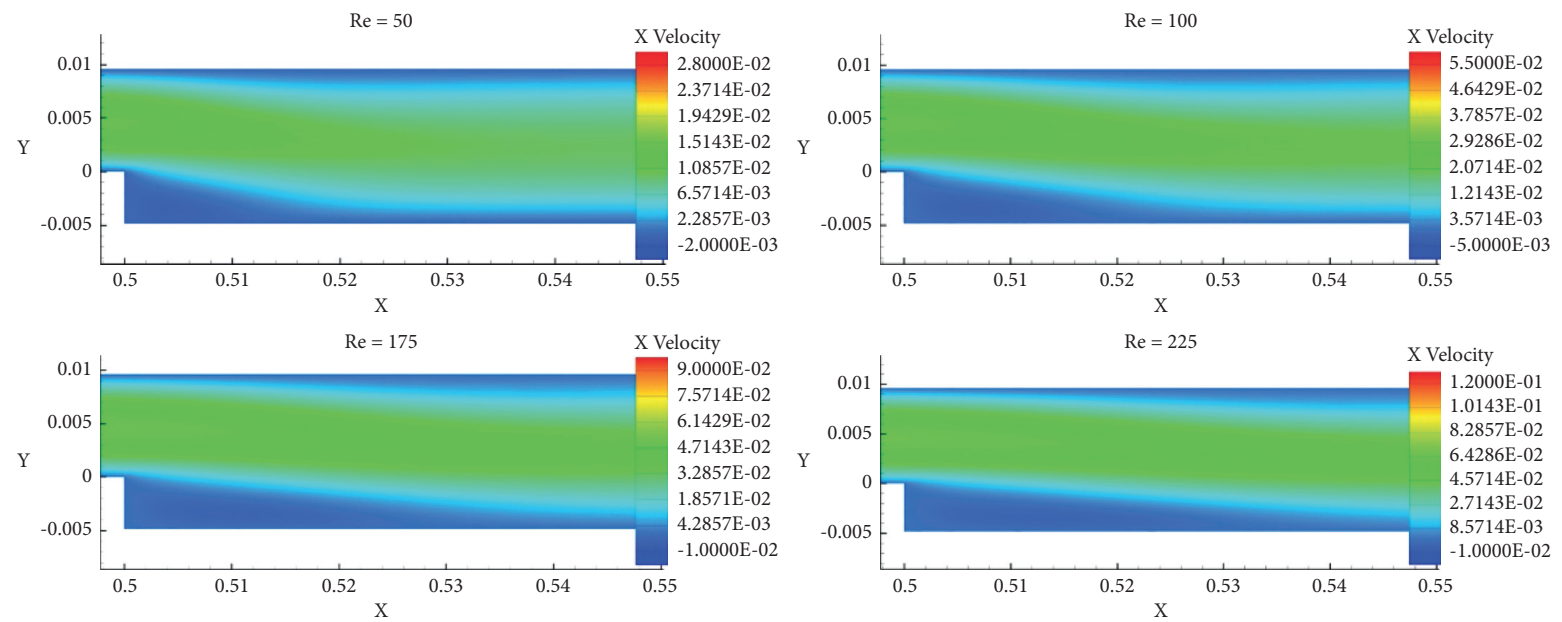

(b)

FIgURE 13: Velocity contours for $\mathrm{SiO}_{2}$ nanofluid with different Reynolds numbers. (a) First step region. (b) Second step region. 

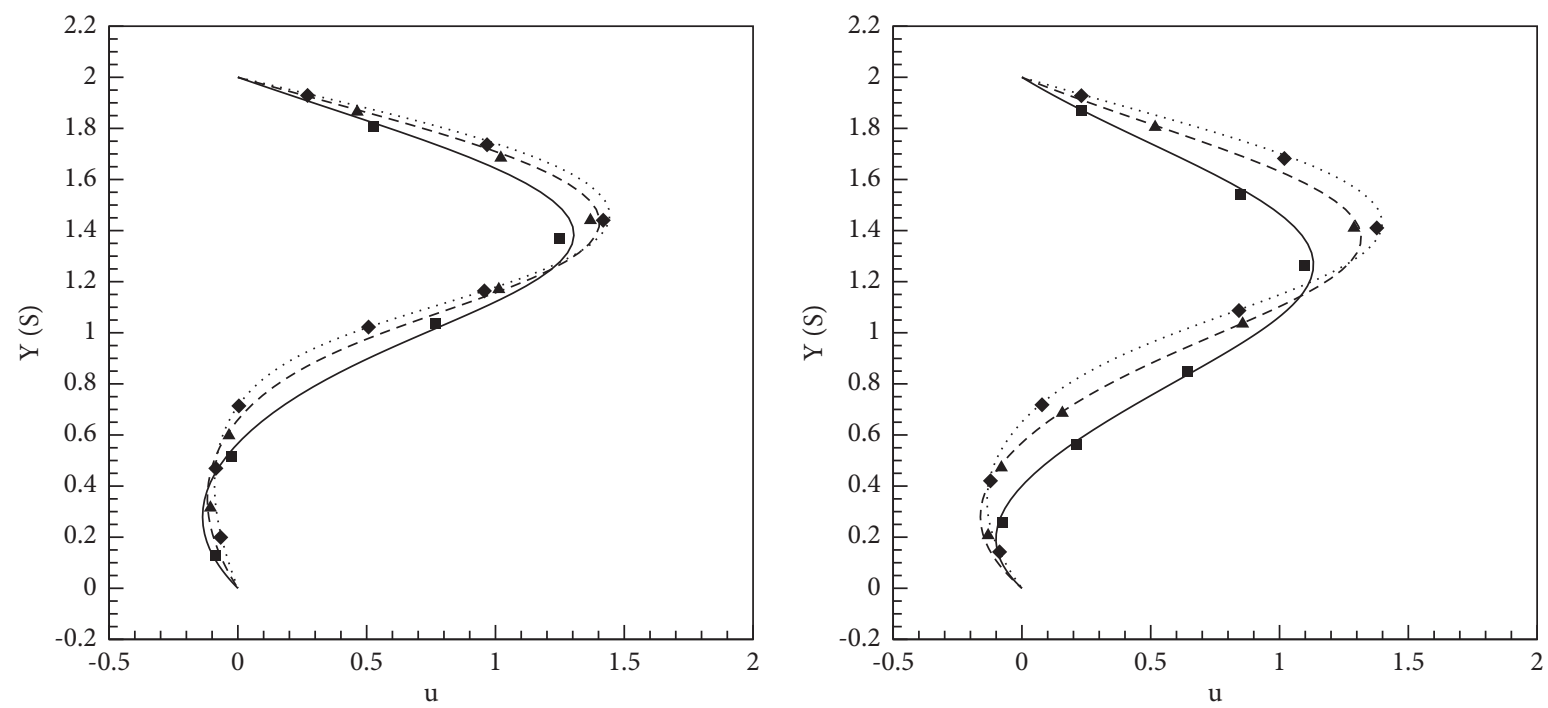

․ $\mathrm{Re}=175$ (Present)

- $\mathrm{Re}=175$ (Al-Aswadi et al. [17])

- - $\mathrm{Re}=100$ (Present)

- $\operatorname{Re}=100$ (Al-Aswadi et al. [17])

- $\mathrm{Re}=50$ (Present)

- $\operatorname{Re}=50$ (Al-Aswadi et al. [17])

(a)
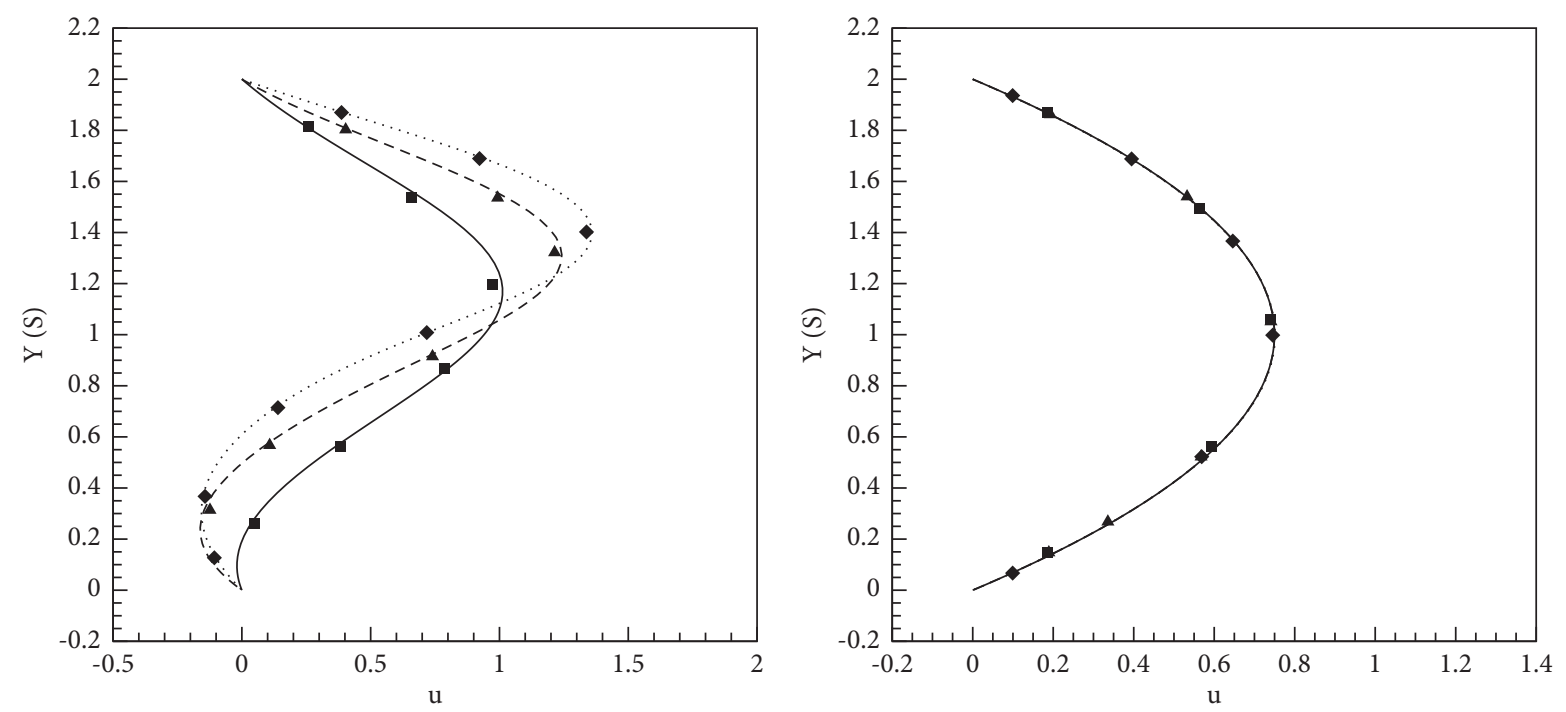

.. $\operatorname{Re}=175$ (Present)

- $\mathrm{Re}=175$ (Al-Aswadi et al. [17])

- - $\mathrm{Re}=100$ (Present)

- $\mathrm{Re}=100$ (Al-Aswadi et al. [17])

$\mathrm{Re}=50$ (Present)

- $\operatorname{Re}=50$ (Al-Aswadi et al. [17])

(c)

… $\operatorname{Re}=175$ (Present)

- $\operatorname{Re}=175$ (Al-Aswadi et al. [17])

- - $\mathrm{Re}=100$ (Present)

- $\operatorname{Re}=100$ (Al-Aswadi et al. [17])

- $\mathrm{Re}=50$ (Present)

- $\operatorname{Re}=50$ (Al-Aswadi et al. [17])

(d)

Figure 14: Comparison of distribution of nondimensional velocity profiles for $\mathrm{Re}=50-175$ at different channel sections for $\mathrm{SiO}_{2}$ nanofluid. (a) $\mathrm{X} / \mathrm{S}=1.04$. (b) $\mathrm{X} / \mathrm{S}=1.92$. (c) $\mathrm{X} / \mathrm{S}=2.6$. (d) $\mathrm{X} / \mathrm{S}=32.8$. 
Al-Aswadi et al. [17] as shown in Figures 14(a)-14(d). It is observed that the present results agree well with the published literature.

\section{Conclusion}

Numerical investigations were carried out to study laminar forced convection of different nanofluids in a double backward-facing step under constant heat flux conditions applied at lower walls of the channel. The study primarily focuses on the comparative analysis of the thermal performance of different nanofluids compared to water resulting from various parameters such as volume fraction and Reynolds number. The key conclusions of this study are listed as follows:

(i) The local Nusselt number increases with the rise in volume fraction and Reynolds number for all working fluids.

(ii) The $\mathrm{SiO}_{2}$ nanofluid shows the highest thermal performance as demonstrated by the highest Nusselt number, followed by $\mathrm{Al}_{2} \mathrm{O}_{3}$ and $\mathrm{ZnO}$ in comparison to water.

(iii) With the increase in Re, the skin friction coefficient decreases for all working fluids. For a particular Re, no significant changes are observed in the values of skin friction coefficient along the heated wall among the working fluids.

(iv) The velocity increases with the rise in $\mathrm{Re}$ for all types of working fluids, with the $\mathrm{SiO}_{2}$ nanofluid having the highest velocity among other working fluids.

\section{Future Works}

Future works can be carried out on the following topics:

(i) Hybrid nanofluids are more efficient in terms of thermal performance compared to base fluids and nanofluids. Due to limited number of research works on hybrid nanofluids, numerical and experimental investigations should be carried out to study thermohydraulic characteristics of hybrid nanofluids in backward- and forward-facing step channels.

(ii) Most of the research works have focused more on the implementation of nanofluids in macroscale backward- and forward-facing step channels. However, more studies should be carried out to study flow and heat transfer using mono/hybrid nanofluids in microscale backward- and forward-facing step channels by implementing numerical and experimental techniques.

(iii) Further studies should be carried out on the turbulent flow and heat transfer of mono/hybrid nanofluids over microscale backward- and forwardfacing step channels.

\section{Data Availability}

The data that support the findings of this study are available upon request from the corresponding author, Mr. Shailendra Rana.

\section{Conflicts of Interest}

The authors declare that they have no conflicts of interest.

\section{Acknowledgments}

The authors are thankful to the Department of Mechanical and Aerospace Engineering, Pulchowk Campus, for the generous support and technical assistance and for providing access to computational resources.

\section{References}

[1] H. A. Mohammed, A. A. Al-Aswadi, N. H. Shuaib, and R. Saidur, "Convective heat transfer and fluid flow study over a step using nanofluids: a review," Renewable and Sustainable Energy Reviews, vol. 15, no. 6, pp. 2921-2939, 2011.

[2] W. Yu, D. M. France, J. L. Routbort, and S. U. S. Choi, "Review and comparison of nanofluid thermal conductivity and heat transfer enhancements," Heat Transfer Engineering, vol. 29, no. 5, pp. 432-460, 2008.

[3] H. A. Mohammed, A. A. Al-aswadi, H. I. Abu-Mulaweh, and N. H. Shuaib, "Influence of nanofluids on mixed convective heat transfer over a horizontal backward-facing step," Heat Transfer-Asian Research, vol. 40, no. 4, pp. 287-307, 2011.

[4] S. Salman, A. R. A. Talib, S. Saadon, and M. T. H. Sultan, "Hybrid nanofluid flow and heat transfer over backward and forward steps: a review," Powder Technology, vol. 363, pp. 448-472, 2020.

[5] H. Togun, M. R. Safaei, R. Sadri et al., "Numerical simulation of laminar to turbulent nanofluid flow and heat transfer over a backward-facing step," Applied Mathematics and Computation, vol. 239, pp. 153-170, 2014.

[6] M. R. Safaei, H. Togun, K. Vafai, S. N. Kazi, and A. Badarudin, "Investigation of heat transfer enhancement in a forwardfacing contracting channel using FMWCNT nanofluids," Numerical Heat Transfer, Part A: Applications, vol. 66, no. 12, pp. 1321-1340, 2014.

[7] H. Togun, G. Ahmadi, T. Abdulrazzaq et al., "Thermal performance of nanofluid in ducts with double forward-facing steps," Journal of the Taiwan Institute of Chemical Engineers, vol. 47, pp. 28-42, 2015.

[8] A. S. Kherbeet, H. A. Mohammed, H. E. Ahmed et al., "Mixed convection nanofluid flow over microscale forward-facing step - effect of inclination and step heights," International Communications in Heat and Mass Transfer, vol. 78, pp. 145-154, 2016.

[9] A. A. A. A. Alrashed, O. A. Akbari, A. Heydari et al., S. Shabani and M. Goodarzi, The numerical modeling of water/FMWCNT nanofluid flow and heat transfer in a backward-facing contracting channel," Physica B: Condensed Matter, vol. 537, pp. 176-183, 2018.

[10] R. Ekiciler, "A CFD investigation of Al2O3/water flow in a duct having backward-facing step," Journal of Thermal Engineering, vol. 5, no. 1, pp. 31-41, 2019.

[11] T. Abuldrazzaq, H. Togun, H. Alsulami, M. Goodarzi, and M. Reza Safaei, "Heat transfer improvement in a double 
backward-facing expanding channel using different working fluids," Symmetry, vol. 12, no. 7, p. 1088, 2020.

[12] P. Bichkar, O. Dandgaval, P. Dalvi, R. Godase, and T. Dey, "Study of shell and tube heat exchanger with the effect of types of baffles," Procedia Manufacturing, vol. 20, pp. 195-200, 2018.

[13] J. H. Nie, Y. T. Chen, and H. T. Hsieh, "Effects of a baffle on separated convection flow adjacent to backward-facing step," International Journal of Thermal Sciences, vol. 48, no. 3, pp. 618-625, 2009.

[14] H. Togun, "Laminar CuO-water nano-fluid flow and heat transfer in a backward-facing step with and without obstacle," Applied Nanoscience, vol. 6, no. 3, pp. 371-378, 2016.

[15] B. Ghasemi and S. M. Aminossadati, "Brownian motion of nanoparticles in a triangular enclosure with natural convection," International Journal of Thermal Sciences, vol. 49, no. 6, pp. 931-940, 2010.

[16] M. Corcione, "Heat transfer features of buoyancy-driven nanofluids inside rectangular enclosures differentially heated at the sidewalls," International Journal of Thermal Sciences, vol. 49, no. 9, pp. 1536-1546, 2010.

[17] A. A. Al-Aswadi, H. A. Mohammed, N. H. Shuaib, and A. Campo, "Laminar forced convection flow over a backward facing step using nanofluids," International Communications in Heat and Mass Transfer, vol. 37, no. 8, pp. 950-957, 2010.

[18] Fluent ANSYS, Fluent 18.0 User's Guide, ANSYS FLUENT Inc., Canonsburg, PA, USA, 2018.

[19] S. V. Patankar, "Numerical Heat Transfer and Fluid Flow", Hemisphere Publishing Corp., Washington, NJ, USA, 1980.

[20] H. K. Versteeg and W. Malalasekera, An Introduction to Computational Fluid Dynamics: The Finite Volume Method, Pearson Education, 2007. 